\title{
Suspected Non-Syndromic Oligodontia - A Rare Case with 13 Agenesis
}

\author{
Dian Lupita Sari, ${ }^{1}$ Seno Pradopo, ${ }^{2}$ Sindy Cornelia Nelwan, ${ }^{2}$ Haryono Utomo ${ }^{3}$ and Udijanto Tedjosasongko ${ }^{2}$ \\ ${ }^{1}$ Pediatric Dentistry Specialistic Program, Faculty of Dental Medicine, Universitas Airlangga, Surabaya, Indonesia \\ ${ }^{2}$ Pediatric Dentistry Department, Faculty of Dental Medicine, Universitas Airlangga, Surabaya, Indonesia \\ ${ }^{3}$ Forensic Odontology Department, Faculty of Dental Medicine, Universitas Airlangga, Surabaya, Indonesia
}

\begin{abstract}
Oligodontia is a condition in which the patient has more than six ageneses, excluding the third molars. Whereas the absence of one tooth is quite common, oligodontia is a rare congenital condition that can happen with or without the syndrome. The condition happens due to disturbances during odontogenesis process. Management of oligodontia is a long-term process, and it involves prosthetic, restorative, and orthodontic treatment to support the oral function and esthetic of the patient. This article aims to report a rare case of agenesis of 13 permanent teeth (excluding third molars) in an 11-year-old girl and her treatment plan.
\end{abstract}

Key Words: oligodontia, anodontia, tooth agenesis

\section{INTRODUCTION}

Tooth agenesis involving a reduction of tooth number, also known as congenitally missing teeth, is caused by a craniofacial malformation. The teeth fail to erupt in the oral cavity and mineralization, which showed with radiopacity, is not visible in radiographs. ${ }^{1}$ It has been reported as the most common anomaly of the craniofacial development in humans, representing a challenging problem to the clinical management, both functional and aesthetic. The teeth absence may be classified depending on the number of the missing dental elements; one to six missing teeth (bypodontia), more than six dental elements missing with both of them excluding third molars (oligodontia), and complete absence of the teeth (anodontia). ${ }^{2}$ Although missing one or two teeth is frequently found, oligodontia is a rare condition. Many pieces of literature stated that incidence of oligodontia relatively low and could vary from $0.08 \%$ to $0.16 \%{ }^{3-5}$ with a higher frequency has been noted in females than males with no difference in the distribution of missing teeth over maxilla/ mandible and left and right sides. ${ }^{6}$

Oligodontia can occur in association with various genetic syndromes such as ectodermal dysplasia, Van Der Woude syndrome, Nance-Horan Syndrome, Down syndrome,

Paper presented at the Joint Scientific Meeting in Special Care Dentistry, July 5, 2019, Amerta Room, 4th Floor, main campus of Universitas Airlangga, Surabaya, Indonesia.

Corresponding author: Seno Pradopo

Department of Pediatric Dentistry

Faculty of Dental Medicine

Universitas Airlangga

J. Mayjen. Prof. Dr. Moestopo No. 47 Surabaya 60132 - Indonesia

Email: seno-p@fkg.unair.ac.id Rieger syndrome, and cleft lip and palate ${ }^{7}$ or as a non-syndromic isolated familial trait, or as an infrequent finding. ${ }^{8}$ Among the syndromic form of oligodontia, ectodermal dysplasia is the most common form. Ectodermal dysplasia has specific characteristics such as sparse hair, dry skin, dystrophic nails, and deficient sweat glands. ${ }^{3}$ Environmental factors such as irradiation, chemotherapeutic agents, or dioxins may arrest tooth development. However, most cases are caused by 
genetic factors as evidenced by association with syndromes, familial clustering, and a higher concordance in monozygotic than in dizygotic twins. ${ }^{9}$ Family studies show that, as an isolated form, both hypodontia and oligodontia may be inherited as an autosomal dominant trait with incomplete penetrance and variable expression. ${ }^{9}$ This article was aimed to report a case of thirteen ageneses of permanent teeth, including all permanent canines, which is a rarity, and its possible treatment plans.

\section{CASE REPORT}

An 11-year-old girl was accompanied by her parents to Universitas Airlangga Dental Hospital due to some teeth agenesis. Her parents stated that she has no history of childhood trauma and not in any medical treatment.
The mother's pregnancy history was normal, and any previous diseases were denied. No family history similar to the patient's case known. The patient was in good mental health and not consuming any drugs at the moment. On extraoral examination, there was no abnormality observed on her eyes, hair, skin, and fingers or toe nails. On intraoral examination, soft tissue was normal, oral hygiene was considered satisfactory, and her palate was found normal. The permanent teeth present were 16, 11, 21, 26, 36, 32, 42, and 46 . There were also retain primary teeth like $55,54,53$, 63, 64, 65, 75, 74, 73, 71, 81, 83, 84, and 85 (Figure 1). All primary teeth were in good condition with no mobility, and upper midline diastema was present. For the radiographic findings, the permanent teeth buds that present were 17,14 , $27,37,34,44$, and 47 only (Figure 2 ), while $15,13,12,22,23$, $24,25,35,33,31,41,43,45$ were absent.
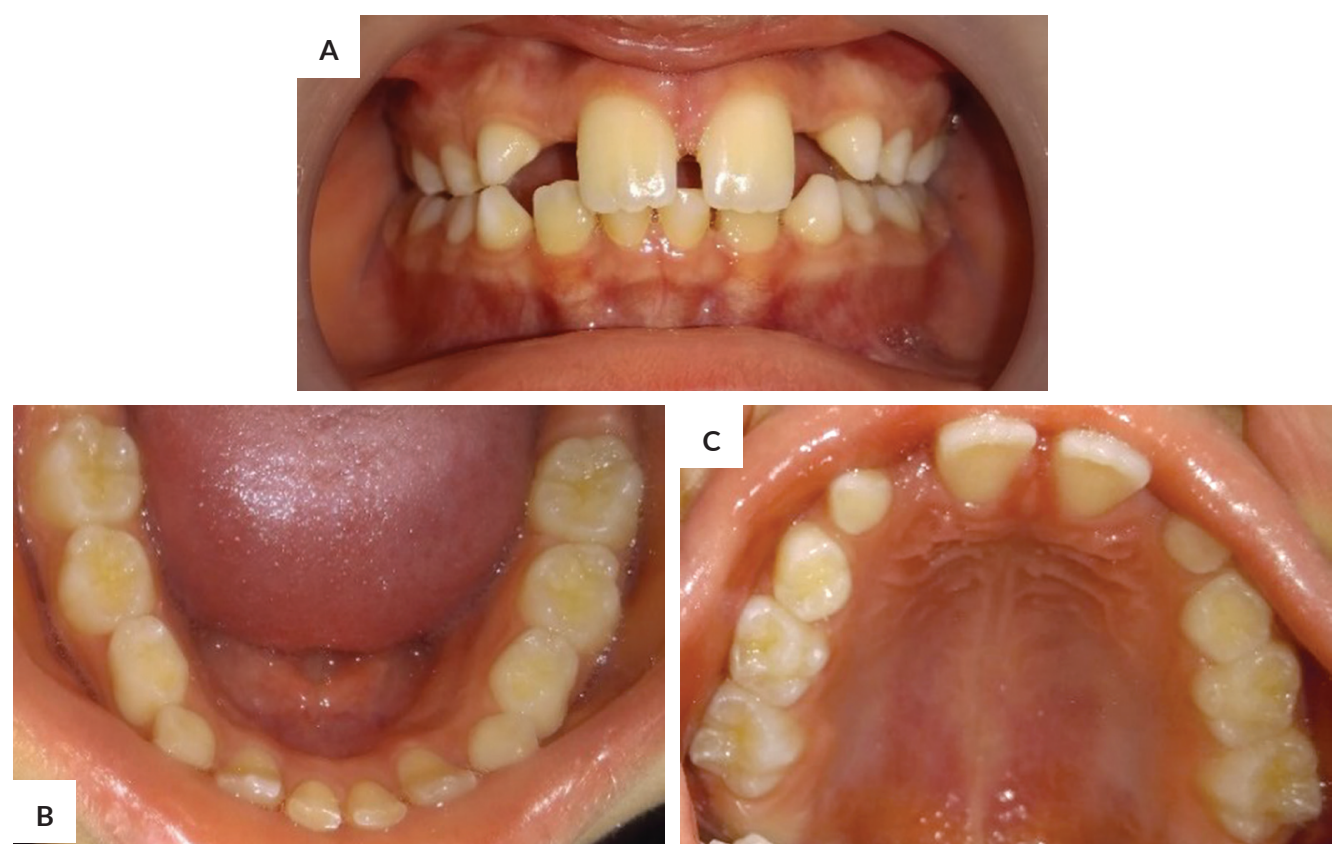

Figure 1. Clinical intraoral condition. (A) Front view, (B) Occlusal view of mandibula, (C) Palatal view.

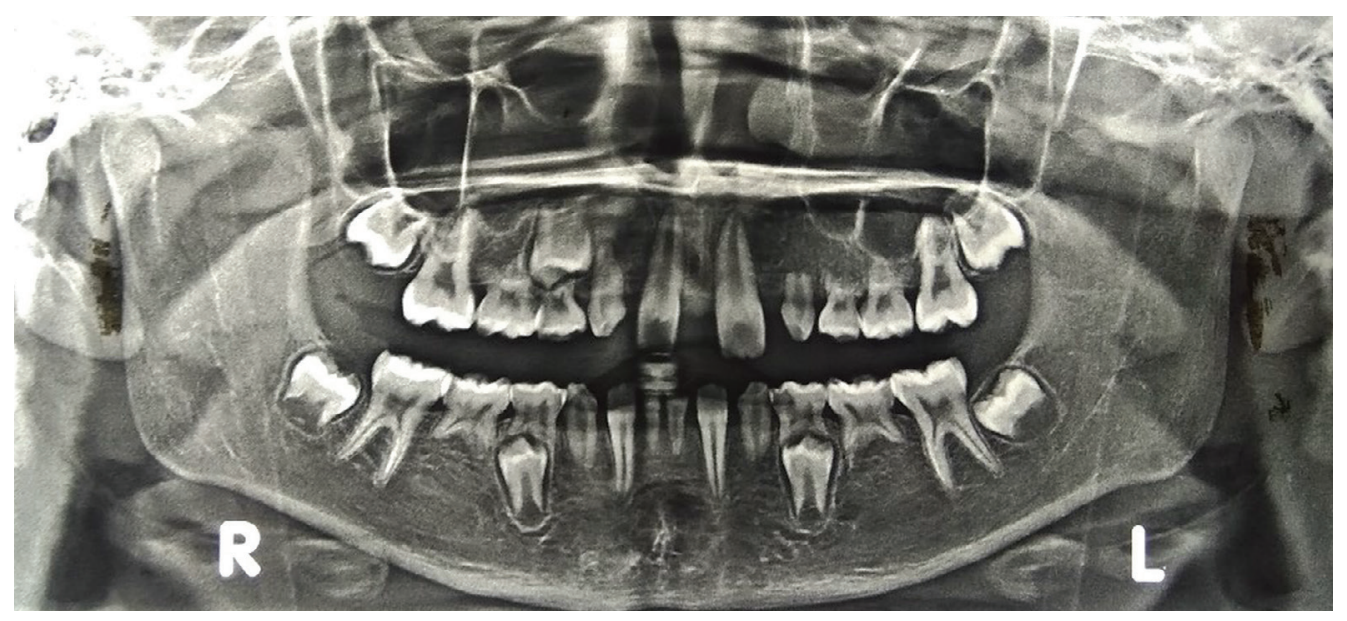

Figure 2. The panoramic photograph showing several ageneses. 
Ectodermal dysplasia and Rieger syndrome were considered as a differential diagnosis but based on the clinical, radiography, and history findings, it was suspected as non-syndromic oligodontia with agenesis of 13 teeth. Further examination, such as genetic analysis and pediatrician consultation, were recommended to confirm the diagnosis. Parents were motivated to do a regular dental follow up, at least once a month, for maintaining the patient's oral function and condition. Meanwhile, the future treatment plan include dental health education and oral hygiene improvement,gradual extraction of retained deciduous teeth, orthodontic treatment for diastema closure followed by prosthetic treatment when all the remaining permanent teeth have erupted.

\section{DISCUSSION}

Oligodontia is the most commonly used term to describe the phenomenon of congenitally missing more than six teeth. Oligodontia has been classified as syndromic and isolated or non-syndromic oligodontia. ${ }^{8}$ In most oligodontia cases that were part of a syndrome, there were usually changes on the skin, nails, eyes, ears, or skeleton. ${ }^{10}$ The pattern of tooth agenesis varies by population. Previous studies conducted among Caucasians report that the lower second premolars and upper lateral incisors are the most commonly missing teeth after third molars, while American blacks have a lower prevalence of congenitally missing teeth than American whites. As for Asians, the most commonly missing teeth after the third molars are the second premolars and mandibular lateral incisors. ${ }^{1}$ The exact etiology for oligodontia is unknown, although various factors have been described in the literature. Heredity is the main factor, but several environmental factors like virus infections, toxins, and radio or chemotherapy may cause missing permanent teeth. However, most of the cases are caused by genetic factors. ${ }^{11}$ Both syndromic and non-syndromic cases, tooth agenesis, are associated with expression disturbs of related genes, particularly the PAX9 and MSX1 genes, which play vital roles in early stages of tooth development. ${ }^{2}$ The critical role of MSX1 and PAX9 is to facilitate the bud to cap stage transition. Loss of function defects in MSX1 and PAX9 in humans cause the partial failure of tooth development which results in tooth agenesis. Defects in MSX1 associate, especially with agenesis of second premolars and third molars, whereas the defects in PAX9 affect particularly the permanent molars. ${ }^{12}$ A research conducted by Daw et al. ${ }^{9}$ in 2016 described a girl with oligodontia and her father with hypodontia. It was found that both affected individuals exhibit typical PAX9 mutation phenotypes. MSX1 and PAX9 have been found to interact synergistically throughout mouse lower incisor development and affect multiple signaling pathways that influence incisor size and symmetry. ${ }^{9}$

In this case report, there were 13 congenitally absent teeth. The patient is a female Asian descendant and in her mixed dentition phase. She did not demonstrate any physical characteristics of the aforementioned syndrome. Therefore, non-syndromic oligodontia was decided as a provisional diagnosis. The agenesis included missing of both lateral upper incisors, both central lower incisors, all canines, left upper first premolar, all second premolars. According to Yadav et al. ${ }^{13}$ agenesis of both upper and lower permanent canines was extremely rare for most cases were missing mandibular or maxillary permanent canine only. ${ }^{13}$ However, in this case, not only congenitally missing thirteen teeth, but amongst those teeth, all four permanent canines were absent. It made this case interesting and promoted to report this to increase awareness among dentists.

There are several treatments which need to be considered in the future management of severe oligodontia cases, especially for patient with mixed dentition stage. ${ }^{14}$ Common issues faced in treating hypodontia patients include space management, up-righting and aligning teeth, and management of the deep overbite. Space issues within the dental arch are multifactorial in origin. The amount of spacing is influenced by the presence of microdontia, retention of the primary teeth, and the abnormal eruptive paths and drifting of the successional teeth. ${ }^{15}$ Replacement of missing teeth is often delayed to await the eruption of the remaining permanent teeth. ${ }^{14} \mathrm{~A}$ definitive treatment plan for replacing the missing teeth should be decided after analyzing the state of the remaining teeth and the interarch relationship. Orthodontic treatment can improve the spatial redistribution of the missing area, rearrangement of teeth, and correction of the tooth axis. ${ }^{7}$ The best time for orthodontic treatment of patients with agenesis of mandibular second premolars is usually early adolescence. This is when most of the remaining developing permanent teeth are erupting, and most of the facial growth has happened. ${ }^{15}$ Prosthetic rehabilitation, removable partial denture, which could be adjusted according to the eruption status of the teeth is a viable option for child patients. ${ }^{10} \mathrm{It}$ promotes social acceptance and restores normal functional demands, such as chewing. ${ }^{16}$

\section{CONCLUSION}

Patients with oligodontia, especially in a mixed dentition stage, may experience psychological, aesthetic, and functional problems that can affect the quality of life. This rare case report is expected to raise awareness and understanding, particularly for dentists. Early diagnosis, systematic treatment selection, and follow-up are critical for young patients as they will undergo long-term treatment. A comprehensive multidisciplinary treatment is needed depending on the severity and the age of the patient.

\section{Statement of Authorship}

All authors participated in data collection and analysis, and approved the final version submitted. 


\section{Author Disclosure}

All authors declared no conflict of interest.

\section{Funding Source}

None.

\section{REFERENCES}

1. Fauzi NH, Ardini YD, Zainuddin Z, Lestari W. A review on nonsyndromic tooth agenesis associated with PAX9 mutations. Jpn Dent Sci Rev. 2018;54(1):30-6.

2. Tomo S, Simonato LE. Non-syndromic oligodontia: a case report. Int J Oral Maxillofac Pathol. 2014; 5(3):17-20.

3. Donald PM, Arora A, George R. Nonsyndromic form of oligodontia in a Chinese male patient: A rare case report. Journal of International Oral Health. 2017; 9(4):180-2.

4. Chakraborty A, Jana S, Dey B, Singh G. Oligodontia of the permanent dentition- A rare case report. Int J Oral Health Med Res. 2017; 4(1):62-4.

5. Basoya S, Koduri S, Gupta I, Chandar VV. Familial non-syndromic oligodontia. J Indian Acad Oral Med Radiol. 2015; 27(3):437-40.

6. Biradar VK, Biradar SV. Non-syndromic oligodontia: report of two cases and literature review. Int J Oral Maxillofac Pathol. 2012; 3(4):48-51.

7. Kang HG, Huh YH, Park CJ, Cho LR. Rehabilitation of a patient with non-syndromic partial oligodontia. J Adv Prosthodont. 2016; 8(3):241-50.
8. Tangade P, Batra M. Non syndromic oligodontia : case report. Ethiop J Health Sci. 2012; 22(3):219-21.

9. Daw EM, Saliba C, Grech G, Camilleri S. A novel PAX9 mutation causing oligodontia. Arch Oral Biol. 2017; 84:100-5.

10. Moses J, Gurunathan D, Rangeeth BN, Kannan KS. Non-syndromic oligodontia of primary and permanent dentition: 5 year follow up-a rare case report. J Clin Diagn Res. 2013; 7(4):776-9.

11. Nagaveni NB, Umashankara KV, Radhika NB, Satisha TS. NonSyndromic oligodontia--report of a clinical case with 14 missing teeth. Bangladesh J Med Sci. 2011; 10(3):200-2.

12. Rahayu YC, Setyorini D. The role of Msx1 and Pax9 in pathogenetic mechanisms of tooth agenesis. Dental Journal (Majalah Kedokteran Gigi). 2009; 42(3):141-6.

13. Yadav SK, Yadav AB, Kedia NB, Singh AK. Agenesis of permanent canines: Rare case report. Dent Res J (Isfahan). 2017; 14(5):359-62.

14. Tong HJ, Tahmassebi JF. Management of a child with severe hypodontia in the mixed dentition stage of development. Eur Arch Paediatr Dent. 2014;15(6):449-54.

15. Al-Ani AH, Antoun JS, Thomson WM, Merriman TR, Farella M. Hypodontia: an update on its etiology, classification, and clinical management. Biomed Res Int. 2017; 2017:9378325.

16. 16. Poornima P, Bajaj M, Bharath KP, Nagaveni NB. Esthetic rehabilitation of non-syndromic oligodontia: An innovative approach. J Adv Clin Res Insights. 2015; 2:184-8. 